\title{
ASSESSMENT OF GENETIC VARIATIONS AND INTERRELATIONSHIPS AMONG AGRONOMIC TRAITS IN ADVANCED BREEDING BARLEY LINES UNDER SALINITY CONDITION
}

\author{
Moustafa, Ehab S.A.
}

Plant Breeding Unit, Department of Genetic Resources, Desert Research Center, El-Matareya, Cairo, Egypt

E-mail: ehab.soudi@yahoo.com

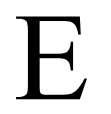

merging of stress-tolerant and high-yielding crops became more decisive especially with presence of global population growing and climatic changes. Improving barley yield in adverse environments, selection of high-yielding genotypes should depend on performance and genetic variability among advanced ones under press as Ras-Sudr salinity water. Proposal materials were 45 advanced barley lines grown in natural salty soil (5000 ppm) and irrigated by naturally saline water at 9000 ppm across 3 seasons (2016-2019). For all traits, genetic parameters; correlations and path coefficient analysis have been assessed. Variance analysis indicated presence of significant differences among all genotypes for all traits in all generations (F5-7) with highness of both phenotypic and genotypic variation coefficients for both yields (grain and biological/fad.) and these support sufficient variation to genetic improvement via selection. Breeding genotypes, their parents and three adopted check cultivars were classified depending on salt-tolerability using hierarchical clustering into three groups; highly, intermediate and tolerant. Furthermore, broad sense heritability $\left(\mathrm{h}^{2}\right)$ for all tested traits ranged from 71.1 to 89.47 in all generations. However phenotypic and genotypic correlation coefficients displayed strong and significant positive associations between grain and biological yields with number of each of: tillers/plant, spikelets/spike and grains/spike and grain weight/spike over the three generations. Moreover, number of each of tillers/plant, spikelets/spike, grains/spike beside biological yield exhibited maximum positive direct effect on grain yield; while the highest indirect effect assigned for biological yield through grain weight/spike and number of each of: tillers/plant, grains/spike and spikelets/spike reflecting importance of them to improve yield.

Keywords: barley, breeding lines, salinity, genetic variability parameters, genotypic and phenotypic correlations, path analysis, yield 
index, hierarchical clustering, principal component analysis, PCbiplot

\section{INTRODUCTION}

On the global scale, barley (Hurdium vulgare L.) was known from ancient times and believed to be firstly originated in Fertile Crescent area of East Mediterranean (Palestine, Jordan, Lebanon, Syria, southeastern Turkey, north Iraq and western Iran) and be domesticated from about 10,000 years ago and traditionally known as poor mans' crop having low input requirements beside better adaptability to harsh environments worldwide (Zohary and Hopf, 1993; Badr et al., 2000; Blattner and Badani, 2001; Bothmer et al., 2003; Ceccarelli et al., 2008; Srivastava et al., 2011 and Abdel-Ghani, 2013). Orabi et al. (2007) reported that Eritrea and Ethiopia are considered as a center of barley diversification. Also, barley is considered as the most important cereal crop in developing countries and about 100 countries cultivate the barley on approximately 56 million hectares (Zhou, 2009) and worldly ranked the fourth after wheat, rice and corn by look to the cultivated area and total production (FAOSTAT, 2020).

The Mediterranean climate is characterized by the fluctuation of water availability as well as salinity ranges. By comparison with other species, the barley especially Hurdeum vulgare L., (the main cereal grown) shows a conservative strategy in water use with moderately salt-tolerable (Gonzalez et al., 1999 and Mohammadi et al., 2010). Also, it represents as one the most nutritive value food that almost equal to wheat and corn specially hull-less for both human and animal as well with having some medicinal properties (Bhatty, 1999; Griffey, 1999 and Baik and Ullrich, 2008). The barley is the main crop grown in a large scale in the North Coastal Region of Egypt plus newly reclaimed lands that suffer from both water shortage and quality. Under different irrigation systems of Egypt, barley production areas increased continuously from 57000 ha $(96,000$ faddan) in the eighties and 137000 ha in 2008/2009 with increasing in its yield from $2.92 \mathrm{t} / \mathrm{ha}$ to $3.63 \mathrm{t} / \mathrm{ha}$ in the same decades and the area reached in 2018 to 168,418 faddan; whereas El-Banna et al. (2011) considered it as the best choice in the risky conditions of poor soils and newly reclaimed areas and is typically cultivated in arid and semi-arid areas that not suitable for the other field crops (Naghii and Asgharipour, 2011).

Hereby, developing of salt tolerant crops is essential for sustaining food production and overcoming the salinity stress (El-Raey, 1997), whereas the water in its normal constituents is essential at every stage of plant growth (Schmidhalter et al., 1998 and Reisdorph and Koster, 1999). Salinity demarcated as an optimal factor that adverse yield production, improvement and adaptation of any crop, whereas crop cultivation in the presence of excess salinity induced disturbance of osmotic regulation, ionic imbalance

Egyptian J. Desert Res., 71, No. 1, 1-22 (2021) 
and oxidative stress that impaired plant metabolism and growth (Barnabas et al., 2008). However, the adaptation is known as a key factor that well shapes the future severity of climatic changes impacts on food production (Lobell et al., 2008). In this hand, the succession of breeding is induced by: identifying the target traits functioned to target growing environment; determining the sources of variability for these traits; crossing these with other varieties that possess other traits of economic importance like resistance and high yield and/or quality and finally testing of these new varieties across a wide range of on-farm environments (Trethowan et al., 2010). Moreover, the improvement of yield components could potentially improve yield stability and/or yield potential under a wide range of environments including specific stresses such as salt ones (Zhu et al., 2020).

The advanced rate of crop improvement depends mainly on the degree of genetic variability existence for various economic traits; whereas genotypic and phenotypic coefficients of variation are effective parameters to investigate genetic variability (Chandra et al., 2003 and Jaradat et al., 2004). The efficiency of any breeding programs depends on the association between grain yield and the other agronomic traits (Srivastava et al., 2011). However heritability estimation gives an idea for the extent of genetic control for the expression of a particular character (Abdel-Ghani et al., 2005) and these parameters provide the reliable magnitude of genetic variability among genotypes and hence constituting the success of selection procedure (Falconer and Mackay, 1996 and Abdel-Ghani, 2013).

The breeding progress might be accelerated if physiological, biochemical and morphological characteristics were used as selection criteria. Simultaneous selection in barley cultivars based on related traits is the most desirable approach to improve characteristics such as grain yield as well as biological yield, in order to determine the most valuable genotypes and the most suitable combination of traits with the intention of improving the yield in different plants as well as identify highly salt tolerant accessions (Siahpoosh et al., 2001; Singh and Balyan, 2003; Chandra et al., 2003; Jaradat et al., 2004; Rabiei et al., 2004; Sabouri et al., 2008; Rezaei and Yousefi, 2008 and Eshghi et al., 2011). In this connection, the barley varieties, advanced breeding lines and germplasms exhibiting improved agronomic performance, disease resistance and abiotic stress tolerance as well as grain quality attributes targeted to malt and feed markets (AbdelGhani 2013). Srivastava et al. (2011) indicated that any breeding or selecting program efficiency depends upon the nature of correlation (which is more directly and positively) between yield and other component characters, so information should include not only the nature and magnitude of variations but also the associations of seed yield with other traits and also among themselves and their causation to identify characters for defining an ideal plant type as well for increasing efficiency of direct and indirect selection.

Egyptian J. Desert Res., 71, No. 1, 1-22 (2021) 
Correlation and path analyses measurements were helpful to obtain a successful breeding program through the determination of the best genotypes having the best traits specially the target ones of grain and biological yields. Whereas the correlation coefficients were useful when the indirect selection of the secondary traits were used to improve the primary traits of interest (Akram et al., 2008) and also to ascertain the relationships between the variables and both yields (Jamshidi and Javanmard, 2018); while the path analysis coefficients were to estimate the inter-connections among the yield contributors and defined the important of them (Savii and Nedelea, 2012).

The best effective approach of fighting against stress is the development of tolerant crop genotypes; therefore the effective goals in this current study are to: (i) compare the yield and its components in forty five barley lines grown in actual salinity field conditions of Ras-Sudr Research Station of Desert Research Center at South Sinai region; (ii) identify highyielding and salt-tolerant barley advanced breeding lines and (iii) evaluate the relationships of yield components with final grain yields and its applications in the selection of most appropriate traits to reach the highest genetic advance under salinity stress.

\section{MATERIALS AND METHODS}

\section{Plant Materials and Experimental Design}

The F5, F6 and F7 advanced generations of forty-five barley breeding lines derived from three-parental crosses, Giza $123 \times$ Giza 2000; Giza $126 \times$ Giza 123 and line SU12330 × Giza 2000, were grown at the Experimental Farm of Desert Research Center, Ras-Sudr Research Station, South Sinai, Egypt $\left(29^{\circ} 35^{\prime} \mathrm{N}, 32^{\circ} 41^{\prime} \mathrm{E}\right)$ with salinity irrigation water (9000 ppm), during 2016/17, 2017/18 and 2018/19 seasons, respectively. The F5 lines were derived from individuals of F4 plants, whereas F6 and F7 lines were produced as seed bulks within lines from F5 and F6 generations, respectively.

The breeding lines (i.e. 15 lines for each cross) were sowing in the last week of Novembers and grown in salty soil (5000 ppm) in a randomized complete block design with 3 replicates. Each line was planted in 6 rows of $2 \mathrm{~m}$ length, $25 \mathrm{~cm}$ apart and irrigated by saline water $(9000 \mathrm{ppm})$ with application of all other recommended agricultural practices in this region.

The data was recorded for days to heading, plant height $(\mathrm{cm})$, number of tillers/plant, stem diameter $(\mathrm{cm})$, length of spike $(\mathrm{cm})$, number of spikelets/spike, number of grains/spike, grain weight/spike (g), 1000 grain weight $(\mathrm{g})$, biological yield/Fadden $(\mathrm{kg})$, and grain yield/Fadden $(\mathrm{kg})$, whereas the mean data were used for statistical analysis. 


\section{Statistical Analysis}

All traits were subjected to analysis of variance (ANOVA) to test the significance of variance sources using XLSTAT2016.05 according to Gomez and Gomez (1984) and the least significant difference (LSD) values were calculated at the 5\% probability level (Steel et al., 1997).

The variance components including phenotypic $\left(\sigma^{2} \mathrm{p}\right)$ and genotypic $\left(\sigma^{2} \mathrm{~g}\right)$ ones were estimated by using the method of Falconer (1989) that depends on the combined data of the three seasons; while the coefficients of phenotypic and genotypic variations (PCV and GCV) were categorized as proposed by Sivasubramanian and Madhavamenon (1973); whereas broad sense heritability was computed as outlined by Walker (1960). Hierarchical cluster analysis was applied using yield index which was calculated using the following equation $\mathrm{YI}=\mathrm{Ys} / \overline{\mathrm{Y}} \mathrm{s}$, where $\mathrm{Ys}$ is the grain yield of each line and $\bar{Y} s$ is the average grain yield of all genotypes. The phenotypic and genotypic correlations were made by the way of Kwon and Torrie (1964) while the confirmatory path analysis of the above mentioned characters on the grain yield was undertaken using the revised method of Dewey and $\mathrm{Lu}$ (1959). Besides, the principal component analysis was performed on the averages of measured traits to investigate the relationships among grain yield and the other agronomic traits.

All descriptive statistics (means, ranges and coefficients of variation; heritability; correlation and path analyses) for all traits and among traits were calculated for all progressive generations using SAS software (SAS Institute Inc., 2003) by using UNIVARIATE and PROC CORR procedures, respectively.

\section{RESULTS AND DISCUSSION}

The successful key in any breeding program is in the inheritance of the most desirable improved characters that were proved by genetic variability and heritability. However, the aim of correlation studies is primarily to know the suitability of various characters for indirect selection, i.e. provide information about the nature and extent of association between any two metric traits and it will be possible to bring about genetic upgrading in one trait by selection of the other of a pair; while the path analysis is an effective way of finding out direct and indirect sources of correlations of different plant attributes (Kashif and Khaliq, 2004).

\section{Genetic Variability Analysis}

The mainly successful factor at any breeding program is genetic variability as well as the heritability of evaluated traits. The obtained results of analysis of variance for studied traits exhibited highly significant differences among evaluated breeding lines in the three generations F5, F6 and F7 (Table 1). Likewise, the results of analysis of both variation 
coefficients (GCV and PCV) shown in Table (2) indicate existence of a wide range of both variations in all selected characters of all studied genotypes in all tested generations with the superiority of F5 and this regarded that these variations were also widely ranged for each individual character (AbdelGhani, 2013). Whereas the highest obtainable recorded scores were for both grain and biological yields/fad in all genotypes in all generations; but in the general concern, the phenotypic view of variation was slightly higher than that of the corresponding genotypic one beside occurrence of low magnitude differences for most investigated traits. These results proved the greater role of genetic components and the phenotypic expression is weakly affected by the environmental factors and so promising the evidence that the improvements of these traits would be successful and effective through selection basing on the phenotypic performance according to the wide of variation among the various investigated characters in all generations. These calculations are compatible with those of Hailu et al. (2016), Oraby et al. (2018), Matin et al. (2019) and Yadav et al. (2019). In the same table, broad sense heritability revealed high measures with highness in its limit values ranged from 71.1 to 89.47 of all traits in most genotypes in the three generations and these probably due to the presence of great differences among the average data of these traits that permit successful selection among them to develop new salt-tolerant genotypes. In this connect the results of Shrimali et al. (2017), Arshadi et al. (2018), Oraby et al. (2018), Matin et al. (2019) and Dyulgerova and Dyulgerov (2020) came in support with ours.

Table (1). Mean squares of studied traits for breeding lines in three generations F5, F6 and F7.

\begin{tabular}{|c|c|c|c|c|c|c|c|c|c|}
\hline & \multicolumn{3}{|c|}{ F5 } & \multicolumn{3}{|c|}{ F6 } & & \multicolumn{2}{|r|}{ F7 } \\
\hline & Lines & Error & Total & Lines & Error & Total & Lines & Error & Total \\
\hline df & 44 & 88 & 134 & 44 & 88 & 134 & 44 & 88 & 134 \\
\hline DH & $37.39^{* *}$ & 1.747 & 13.80 & $31.79^{* *}$ & 1.671 & 12.16 & $29.62^{* *}$ & 1.031 & 11.40 \\
\hline $\mathbf{P H}$ & $105.8^{* *}$ & 4.669 & 43.86 & $172.6^{* *}$ & 1.413 & 63.64 & $122.1^{* *}$ & 5.175 & 44.95 \\
\hline NT/P & $0.835^{* *}$ & 0.085 & 0.379 & $0.805^{* *}$ & 0.109 & 0.553 & $0.758^{* *}$ & 0.057 & 0.487 \\
\hline SD & $0.512^{* *}$ & 0.062 & 0.227 & $0.436^{* *}$ & 0.015 & 0.260 & $0.239^{* *}$ & 0.017 & 0.190 \\
\hline SL & $2.254^{* *}$ & 0.029 & 0.831 & $2.181^{* *}$ & 0.027 & 0.809 & $2.192^{* *}$ & 0.027 & 0.971 \\
\hline NS/S & $16.43^{* *}$ & 1.092 & 6.225 & $15.16^{* *}$ & 0.846 & 6.598 & $12.66^{* *}$ & 0.879 & 4.939 \\
\hline NG/S & $182.3^{* *}$ & 2.034 & 62.23 & $167.58^{* *}$ & 2.339 & 60.51 & $160.90^{* *}$ & 1.696 & 65.87 \\
\hline GW/S & $0.601^{* *}$ & 0.008 & 0.214 & $0.546^{* *}$ & 0.008 & 0.422 & $0.517^{* *}$ & 0.001 & 0.185 \\
\hline TGW & $57.40^{* *}$ & 0.036 & 21.26 & $67.01^{* *}$ & 12.09 & 30.17 & $43.61^{* *}$ & 0.174 & 16.41 \\
\hline GY & $33789^{* *}$ & 24.163 & 11295 & $3131.9^{* *}$ & 20.74 & 1076 & $2498.4^{* *}$ & 22.61 & 8.356 \\
\hline BY & $54809^{* *}$ & 41.136 & 18359 & $44752.0^{* *}$ & 18.31 & 14954 & $37083.9^{\text {** }}$ & 34.01 & 0.678 \\
\hline
\end{tabular}

DH: days to heading, PH: plant height, NT/P: number of tillers/plant, SD: stem diameter, SL: spike length, NS/S: number of spikelets/spike, NG/S: number of grains/spike, GW: grain weight/spike, TGW: 1000-grain weight, GY: grain yield (kg/fad), BY: biological yield $\left(\mathrm{kg} /\right.$ fad) harvest index. ${ }^{* *}$ indicates $p$-value $<0.01$.

Egyptian J. Desert Res., 71, No. 1, 1-22 (2021) 


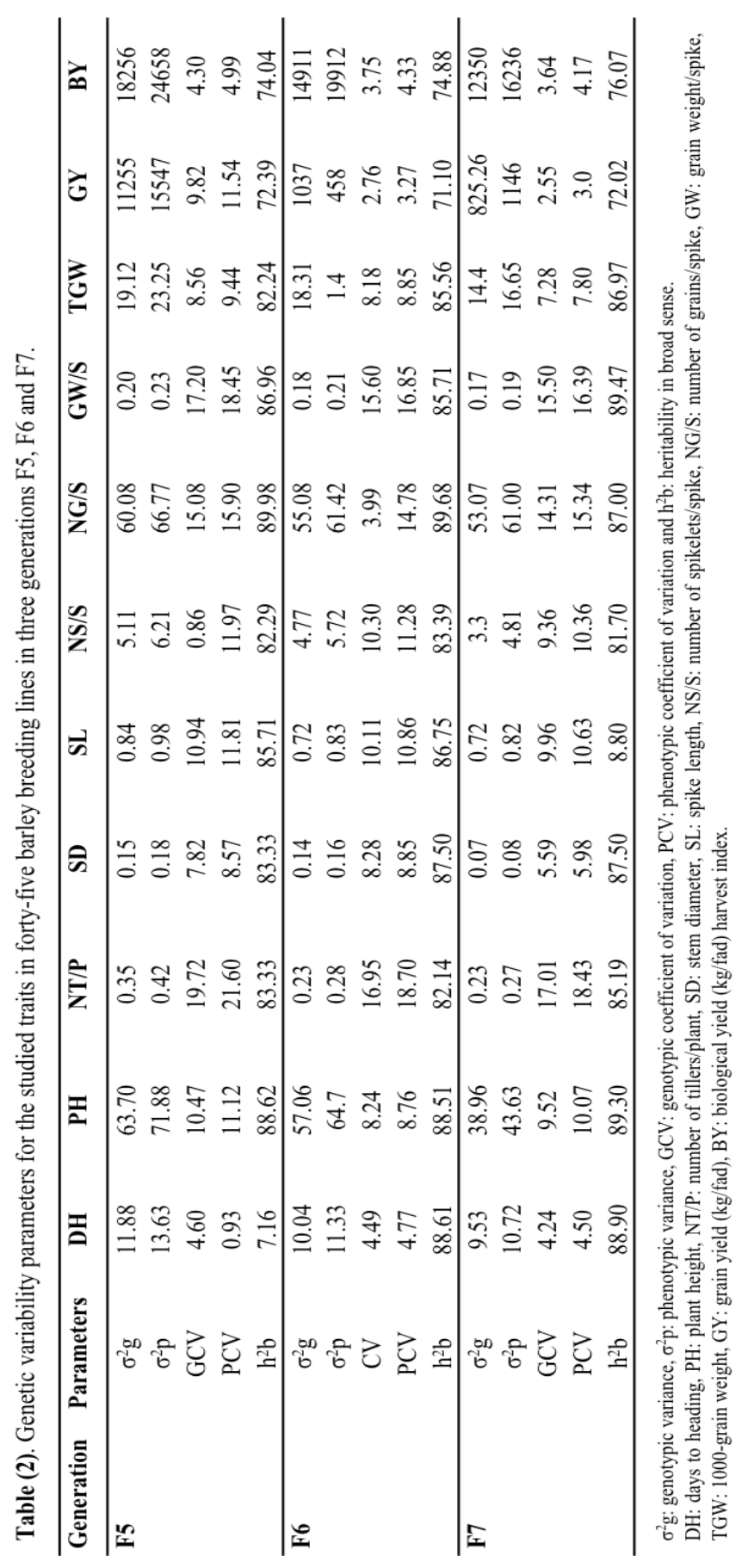

Egyptian J. Desert Res., 71, No. 1, 1-22 (2021) 


\section{Yield Index and Cluster Analysis}

Yield index was calculated for the evaluated breeding lines, their parents and three commercial check cultivars (Table 3). The genotypes that showed the greatest yield index are considered salt-tolerant genotypes. Based on yield index, the genotypes were classified into three groups using hierarchical clustering (Fig. 1). Group A comprised of 10 breeding lines with the highest observed yield index; therefore, it could be considered as a highly salt-tolerant genotype. Group B had 20 genotypes (18 breeding lines and two commercial cultivars) with high tolerance index values, hence, they are considered salt-tolerant genotypes. Similarly, Group C is composed of 22 genotypes (17 breeding lines, 4 commercial cultivars and exotic genotype) that had intermediate tolerance indices values and they are considered moderate-tolerant genotypes. Various researchers applied hierarchical clustering efficiently to classify the genotypes according to their tolerance as Hammami et al. (2016) and Mansour et al. (2017 and 2020).

Table (3). Grain yield (kg/fad) and yield index (YI) for 45 breeding lines, their four parents and three commercial check cultivars over three growing seasons.

\begin{tabular}{|c|c|c|c|c|c|c|c|}
\hline Genotype & Parents & Grain yield & YI & Genotype & Parents & Grain yield & YI \\
\hline L1 & $\mathrm{P} 1 \times \mathrm{P} 2$ & 1192 & 1.09 & L27 & $\mathrm{P} 3 \times \mathrm{P} 1$ & 1381 & 1.26 \\
\hline L2 & $\mathrm{P} 1 \times \mathrm{P} 2$ & 687 & 0.63 & L28 & $\mathrm{P} 3 \times \mathrm{P} 1$ & 1470 & 1.35 \\
\hline L3 & $\mathrm{P} 1 \times \mathrm{P} 2$ & 1282 & 1.17 & L29 & $\mathrm{P} 3 \times \mathrm{P} 1$ & 836 & 0.77 \\
\hline L4 & $\mathrm{P} 1 \times \mathrm{P} 2$ & 1153 & 1.06 & L30 & $\mathrm{P} 3 \times \mathrm{P} 1$ & 1037 & 0.95 \\
\hline L5 & $\mathrm{P} 1 \times \mathrm{P} 2$ & 535 & 0.49 & L31 & $\mathrm{P} 4 \times \mathrm{P} 2$ & 1486 & 1.36 \\
\hline L6 & $\mathrm{P} 1 \times \mathrm{P} 2$ & 1229 & 1.13 & L32 & $\mathrm{P} 4 \times \mathrm{P} 2$ & 779 & 0.71 \\
\hline L7 & $\mathrm{P} 1 \times \mathrm{P} 2$ & 1206 & 1.10 & L33 & $\mathrm{P} 4 \times \mathrm{P} 2$ & 1214 & 1.11 \\
\hline L8 & $\mathrm{P} 1 \times \mathrm{P} 2$ & 649 & 0.59 & L34 & $\mathrm{P} 4 \times \mathrm{P} 2$ & 1236 & 1.13 \\
\hline L9 & $\mathrm{P} 1 \times \mathrm{P} 2$ & 1062 & 0.97 & L35 & $\mathrm{P} 4 \times \mathrm{P} 2$ & 494 & 0.45 \\
\hline L10 & $\mathrm{P} 1 \times \mathrm{P} 2$ & 1623 & 1.49 & L36 & $\mathrm{P} 4 \times \mathrm{P} 2$ & 942 & 0.86 \\
\hline L11 & $\mathrm{P} 1 \times \mathrm{P} 2$ & 826 & 0.76 & L37 & $\mathrm{P} 4 \times \mathrm{P} 2$ & 1101 & 1.01 \\
\hline L12 & $\mathrm{P} 1 \times \mathrm{P} 2$ & 1302 & 1.19 & L38 & $\mathrm{P} 4 \times \mathrm{P} 2$ & 1033 & 0.95 \\
\hline L13 & $\mathrm{P} 1 \times \mathrm{P} 2$ & 1496 & 1.37 & L39 & $\mathrm{P} 4 \times \mathrm{P} 2$ & 756 & 0.69 \\
\hline L14 & $\mathrm{P} 1 \times \mathrm{P} 2$ & 776 & 0.71 & L40 & $\mathrm{P} 4 \times \mathrm{P} 2$ & 912 & 0.84 \\
\hline L15 & $\mathrm{P} 1 \times \mathrm{P} 2$ & 1106 & 1.01 & L41 & $\mathrm{P} 4 \times \mathrm{P} 2$ & 825 & 0.76 \\
\hline
\end{tabular}

Egyptian J. Desert Res., 71, No. 1, 1-22 (2021) 
Table (3). Cont.

\begin{tabular}{|c|c|c|c|c|c|c|c|}
\hline L16 & $\mathrm{P} 3 \times \mathrm{P} 1$ & 1627 & 1.49 & L42 & $\mathrm{P} 4 \times \mathrm{P} 2$ & 954 & 0.87 \\
\hline L17 & $\mathrm{P} 3 \times \mathrm{P} 1$ & 736 & 0.67 & L43 & $\mathrm{P} 4 \times \mathrm{P} 2$ & 1129 & 1.03 \\
\hline L18 & $\mathrm{P} 3 \times \mathrm{P} 1$ & 1655 & 1.52 & L44 & $\mathrm{P} 4 \times \mathrm{P} 2$ & 1123 & 1.03 \\
\hline L19 & $\mathrm{P} 3 \times \mathrm{P} 1$ & 1920 & 1.76 & L45 & $\mathrm{P} 4 \times \mathrm{P} 2$ & 1096 & 1.00 \\
\hline L20 & $\mathrm{P} 3 \times \mathrm{P} 1$ & 837 & 0.77 & Giza-131 & Check & 645 & 0.59 \\
\hline L21 & $\mathrm{P} 3 \times \mathrm{P} 1$ & 1642 & 1.50 & Giza-133 & Check & 919 & 0.84 \\
\hline L22 & $\mathrm{P} 3 \times \mathrm{P} 1$ & 1873 & 1.72 & Giza-134 & Check & 1323 & 1.21 \\
\hline L23 & $\mathrm{P} 3 \times \mathrm{P} 1$ & 800 & 0.73 & Giza-123 & Parent & 1008 & 0.92 \\
\hline L24 & $\mathrm{P} 3 \times \mathrm{P} 1$ & 1194 & 1.09 & Giza-126 & Parent & 790 & 0.72 \\
\hline L25 & $\mathrm{P} 3 \times \mathrm{P} 1$ & 1502 & 1.38 & Giza-2000 & Parent & 873 & 0.80 \\
\hline L26 & $\mathrm{P} 3 \times \mathrm{P} 1$ & 863 & 0.79 & line-SU12330 & Parent & 655 & 0.60 \\
\hline \multicolumn{2}{|c|}{ LSD $_{0.05 \%}$} & 146.9 & & & & & \\
\hline
\end{tabular}

P1 is Giza-123, P2 is Giza-2000, P3 is Giza-126 and P4 is line-SU12330

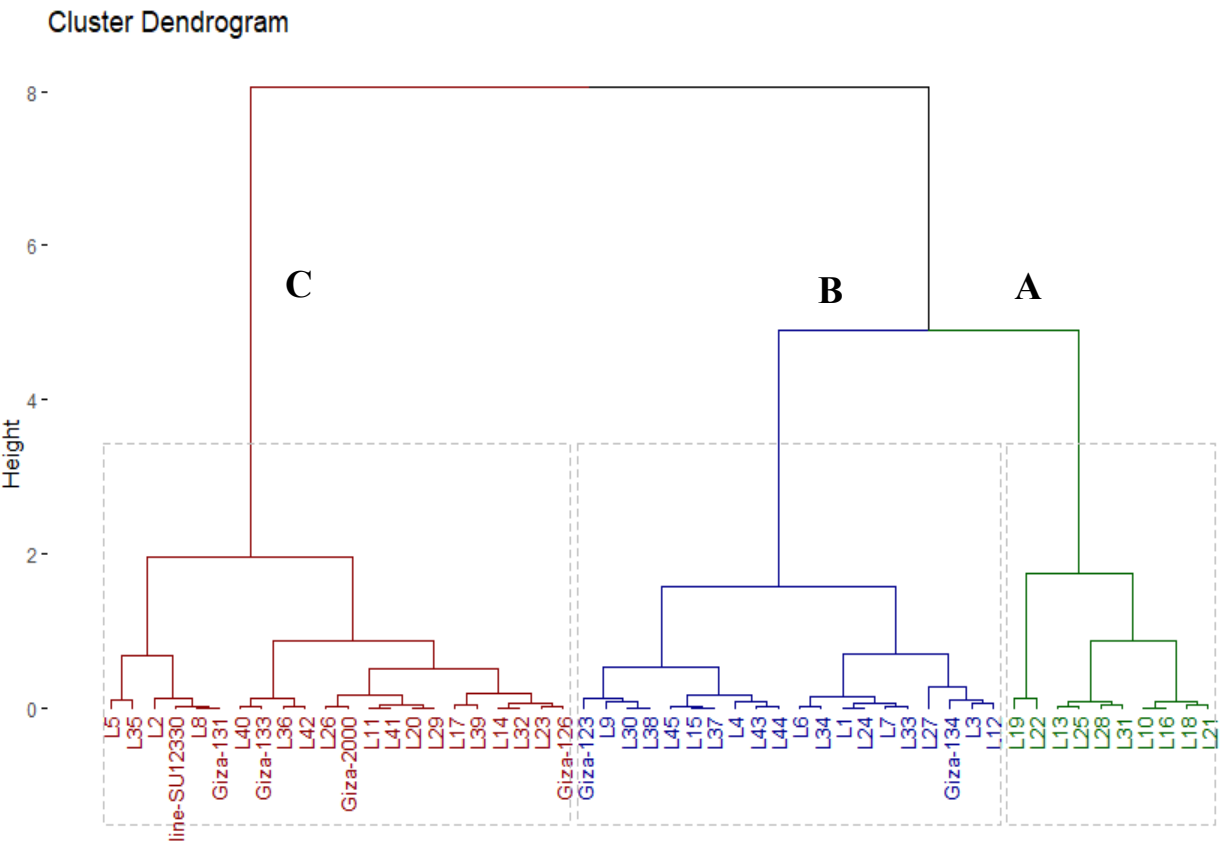

Fig. (1). Dendrogram of phenotypic distances among 45 breeding lines, their four parents and three check cultivars based on yield index. 


\section{Interrelationships Among Studied Traits}

Correlation aims primarily to identify the suitability of studied traits for selection while phenotypic and genotypic correlation coefficients provide information about the nature and extent of the association between traits. The tables (4-6) sustained the existence of significant and/or highly significant positive connections in the fifth generation between the grain yield/fad with the biological yield/fad and each of: numbers of plant tillers and both spikelets and grains/spike as well as spike grain weight; and the last trait (grain weight/spike) was recorded the same correlations with each of the other before-mentioned ones; and the same correlations were also persist for each of: number of tillers/plant, spike length and spikelets number/spike with number of grains/spike besides its associations with the both main traits (grain and biological yields/fad) and also number of spikelets/spike was typically correlated with both stem diameter and spike length; and in the same way plant height associated with the 1000 grain weight; but the negative connections were found in the last trait with spike length and also in the biological yield/fad with days to heading; while the last mentioned one was positively correlated with stem diameter. Lately in the same line, positive significant and/or highly significant relationships also occurred in the sixth generation between the main targeted characters (both yields/fad) with each of the same traits that mentioned in F5 plus plant height whereas the last one correlated significantly positive only; also grain weight/spike recorded the same correlation with the same traits as in the F5; in the meantime each of: number of tillers/plant, number of spikelets/spike and spike length were likely associated with number of grains/spike. The same connections were detected for number of spikelets/spike with both of: number of tillers/plant as well as spike length. On the other hand, the negative and highly significant associations were noticed in days to heading with each of: grain yield/fad, biological yield/fad, grain weight/spike and the 1000 grain weight; while the last trait had also negative significant correlation with spike length. Finally, from the general picture of F7, it could be concluded that exactly the same type of correlations for both: grain and biological yields/fad, spike grain weight as well as numbers of both spikelets and grains/spike was observed with the same characters those previously mentioned in the F5. While number of spikelets/spike have shown this type of association (positive and significant and/or highly significant) with both of number of tillers/plant and spike length. On the other hand, both yields/fad, 1000 grain weight and grain weight/spike were negatively and significantly correlated by days to heading and the same doing for plant height with spike (grain weight and both grains and spikelets numbers). Whereas the 1000 grain weight showed significant and/or highly significant negative correlation with stem diameter. These observations are in consistence with those of Mohtashami (2015), Tofiq et al. (2015 and 2016), Amardeep et al. (2017), Sunil et al. (2017), Malik et al. (2018), Allel et al.

Egyptian J. Desert Res., 71, No. 1, 1-22 (2021) 
(2019), Ghimire and Mahat (2019), Yadav et al. (2019) and Dyulgerova and Dyulgerov (2020).

Table (4). Genotypic and phenotypic correlation coefficients for the evaluated agronomic traits in forty-five barley breeding lines in generation F5.

\begin{tabular}{|c|c|c|c|c|c|c|c|c|c|c|c|}
\hline Trait & Correlation & DH & PH & $\mathbf{N T} / \mathbf{P}$ & SD & SL & NS/S & NG/S & GW/S & TGW & BY \\
\hline \multirow{2}{*}{ PH } & $\mathbf{R g}$ & 0.07 & & & & & & & & & \\
\hline & Rph & 0.07 & & & & & & & & & \\
\hline \multirow{2}{*}{ NT/P } & $\mathbf{R g}$ & -0.3 & 0.08 & & & & & & & & \\
\hline & Rph & -0.23 & 0.21 & & & & & & & & \\
\hline \multirow{2}{*}{ SD } & $\mathbf{R g}$ & $0.39^{*}$ & 0.03 & -0.11 & & & & & & & \\
\hline & Rph & 0.27 & 0.04 & -0.07 & & & & & & & \\
\hline \multirow{2}{*}{ SL } & $\mathbf{R g}$ & 0.17 & 0.07 & 0.21 & 0.25 & & & & & & \\
\hline & Rph & 0.16 & 0.06 & 0.18 & 0.2 & & & & & & \\
\hline \multirow{2}{*}{ NS/S } & Rg & -0.17 & -0.2 & 0.30 & $0.33^{*}$ & $0.39^{*}$ & & & & & \\
\hline & Rph & -0.12 & -0.2 & 0.25 & 0.24 & $0.35^{*}$ & & & & & \\
\hline \multirow{2}{*}{ NG/S } & $\mathbf{R g}$ & -0.19 & -0.07 & $0.43^{* *}$ & 0.18 & $0.39^{*}$ & $0.68^{* *}$ & & & & \\
\hline & Rph & -0.19 & -0.07 & $0.35^{*}$ & 0.15 & $0.38^{*}$ & $0.61^{* *}$ & & & & \\
\hline \multirow{2}{*}{ GW/S } & Rg & -0.24 & 0.09 & $0.35^{*}$ & 0.15 & 0.22 & $0.63^{* *}$ & $0.76^{* *}$ & & & \\
\hline & Rph & -0.22 & 0.01 & 0.32 & 0.12 & 0.21 & $0.54^{* *}$ & $0.74^{* *}$ & & & \\
\hline \multirow{2}{*}{ TGW } & Rg & -0.21 & $0.46^{* *}$ & -0.05 & -0.2 & $-0.33^{*}$ & -0.24 & -0.23 & 0.11 & & \\
\hline & Rph & -0.19 & $0.43^{* *}$ & -0.04 & -0.17 & $-0.33^{*}$ & -0.22 & -0.23 & 0.11 & & \\
\hline \multirow{2}{*}{ BY } & Rg & $-0.34^{*}$ & 0.08 & $0.55^{* *}$ & 0.24 & 0.23 & $0.47^{* *}$ & $0.49^{* *}$ & $0.52^{* *}$ & -0.08 & \\
\hline & Rph & -0.32 & 0.06 & $0.47^{* *}$ & 0.2 & 0.22 & $0.42^{* *}$ & $0.48^{* *}$ & $0.51^{* *}$ & -0.08 & \\
\hline \multirow{2}{*}{ GY } & Rg & -0.27 & -0.04 & $0.54^{* *}$ & 0.24 & 0.14 & $0.45^{* *}$ & $0.52^{* *}$ & $0.45^{* *}$ & -0.06 & $0.84^{* *}$ \\
\hline & Rph & -0.25 & -0.04 & $0.47^{* *}$ & 0.2 & 0.13 & $0.41^{* *}$ & $0.51^{* *}$ & $0.43^{* *}$ & -0.06 & $0.83^{* *}$ \\
\hline
\end{tabular}

DH: days to heading, PH: plant height, NT/P: number of tillers/plant, SD: stem diameter, SL: spike length, NS/S: number of spikelets/spike, NG/S: number of grains/spike, GW: grain weight/spike, TGW: 1000-grain weight, GY: grain yield ( $\mathrm{kg} / \mathrm{fad}), \mathrm{BY}$ : biological yield $(\mathrm{kg} / \mathrm{fad})$ harvest index. 
Table (5). Genotypic and phenotypic correlation coefficients for the evaluated agronomic traits in forty-five barley breeding lines in generation F6.

\begin{tabular}{|c|c|c|c|c|c|c|c|c|c|c|c|}
\hline Trait & Correlation & DH & $\mathbf{P H}$ & NT/P & SD & SL & $\mathrm{NS} / \mathrm{S}$ & NG/S & GW/S & TGW & BY \\
\hline \multirow{2}{*}{ PH } & $\mathbf{R g}$ & -0.17 & & & & & & & & & \\
\hline & Rph & -0.16 & & & & & & & & & \\
\hline \multirow{2}{*}{ NT/P } & $\mathbf{R g}$ & -0.18 & 0.09 & & & & & & & & \\
\hline & Rph & -0.16 & 0.08 & & & & & & & & \\
\hline \multirow{2}{*}{ SD } & $\mathbf{R g}$ & 0.24 & -0.09 & -0.15 & & & & & & & \\
\hline & Rph & 0.21 & -0.09 & -0.12 & & & & & & & \\
\hline \multirow{2}{*}{ SL } & $\mathbf{R g}$ & 0.17 & -0.01 & 0.21 & -0.06 & & & & & & \\
\hline & Rph & 0.15 & -0.01 & 0.18 & -0.05 & & & & & & \\
\hline \multirow{2}{*}{ NS/S } & Rg & -0.04 & 0.04 & $0.34^{*}$ & -0.14 & $0.49^{* *}$ & & & & & \\
\hline & Rph & -0.01 & 0.03 & 0.31 & -0.13 & $0.46^{* *}$ & & & & & \\
\hline \multirow{2}{*}{ NG/S } & Rg & -0.23 & 0.12 & $0.41^{*}$ & -0.23 & $0.38^{*}$ & $0.55^{* *}$ & & & & \\
\hline & Rph & -0.21 & 0.11 & $0.37^{*}$ & -0.21 & $0.36^{*}$ & $0.50^{* *}$ & & & & \\
\hline \multirow{2}{*}{ GW/S } & $\mathbf{R g}$ & $-0.44^{* *}$ & 0.07 & $0.60^{* *}$ & -0.20 & 0.15 & $0.50^{* *}$ & $0.79^{* *}$ & & & \\
\hline & Rph & $-0.40^{*}$ & 0.07 & $0.53^{* *}$ & -0.18 & 0.14 & $0.45^{* *}$ & $0.76^{* *}$ & & & \\
\hline \multirow{2}{*}{ TGW } & $\mathbf{R g}$ & $-0.47^{* *}$ & 0.12 & 0.08 & -0.04 & $-0.36^{*}$ & -0.27 & -0.05 & 0.28 & & \\
\hline & Rph & -0.28 & 0.07 & 0.15 & -0.06 & -0.25 & -0.13 & -0.04 & 0.24 & & \\
\hline \multirow{2}{*}{ BY } & $\mathbf{R g}$ & $-0.47^{* *}$ & $0.38^{*}$ & $0.58^{* *}$ & -0.28 & 0.18 & $0.51^{* *}$ & $0.49^{* *}$ & $0.64^{* *}$ & -0.02 & \\
\hline & Rph & $-0.43^{* *}$ & $0.37^{*}$ & $0.52^{* *}$ & -0.27 & 0.18 & $0.47^{* *}$ & $0.48^{* *}$ & $0.62^{* *}$ & -0.01 & \\
\hline \multirow{2}{*}{ GY } & $\mathbf{R g}$ & $-0.43^{* *}$ & $0.34^{*}$ & $0.74^{* *}$ & -0.26 & 0.12 & $0.58^{* *}$ & $0.44^{* *}$ & $0.67^{* *}$ & 0.02 & $0.86^{* *}$ \\
\hline & Rph & $-0.40^{*}$ & $0.34^{*}$ & $0.66^{* *}$ & -0.25 & 0.12 & $0.53^{* *}$ & $0.43^{* *}$ & $0.66^{* *}$ & 0.01 & $0.86^{* *}$ \\
\hline
\end{tabular}

DH: days to heading, PH: plant height, NT/P: number of tillers/plant, SD: stem diameter, SL: spike length, NS/S: number of spikelets/spike, NG/S: number of grains/spike, GW: grain weight/spike, TGW: 1000-grain weight, GY: grain yield (kg/fad), BY: biological yield $(\mathrm{kg} / \mathrm{fad})$ harvest index. 
Table (6). Genotypic and phenotypic correlation coefficients for the evaluated agronomic traits in forty-five barley breeding lines in generation F7.

\begin{tabular}{|c|c|c|c|c|c|c|c|c|c|c|c|}
\hline Trait & Correlation & DH & PH & NT/P & SD & SL & $\mathbf{N S} / \mathrm{S}$ & NG/S & GW/S & TGW & BY \\
\hline \multirow[b]{2}{*}{ PH } & $\mathbf{R g}$ & -0.13 & & & & & & & & & \\
\hline & Rph & -0.12 & & & & & & & & & \\
\hline \multirow{2}{*}{ NT/P } & $\mathbf{R g}$ & -0.29 & -0.15 & & & & & & & & \\
\hline & Rph & -0.27 & -0.13 & & & & & & & & \\
\hline \multirow{2}{*}{ SD } & $\mathbf{R g}$ & 0.30 & 0.02 & 0.04 & & & & & & & \\
\hline & Rph & 0.24 & 0.04 & 0.03 & & & & & & & \\
\hline \multirow{2}{*}{ SL } & Rg & 0.19 & -0.15 & 0.2 & 0.08 & & & & & & \\
\hline & Rph & 0.18 & -0.14 & 0.19 & 0.07 & & & & & & \\
\hline \multirow{2}{*}{$\mathrm{NS} / \mathrm{S}$} & Rg & -0.12 & $-0.34^{*}$ & $0.39^{*}$ & 0.18 & $0.43^{* *}$ & & & & & \\
\hline & Rph & -0.11 & -0.3 & 0.3 & 0.16 & $0.39^{* *}$ & & & & & \\
\hline \multirow{2}{*}{ NG/S } & Rg & -0.21 & $-0.36^{*}$ & $0.36^{*}$ & -0.03 & $0.35^{*}$ & $0.60^{* *}$ & & & & \\
\hline & Rph & -0.20 & $-0.34^{*}$ & $0.33^{*}$ & -0.02 & $0.34^{*}$ & $0.53^{* *}$ & & & & \\
\hline \multirow{2}{*}{ GW/S } & $\mathbf{R g}$ & $-0.39^{*}$ & $-0.34^{*}$ & $0.36^{*}$ & -0.11 & 0.15 & $0.46^{* *}$ & $0.82^{* *}$ & & & \\
\hline & Rph & $-0.37^{*}$ & $-0.33^{*}$ & 0.32 & -0.09 & 0.15 & $0.42^{* *}$ & $0.81^{* *}$ & & & \\
\hline \multirow{2}{*}{ TGW } & $\mathbf{R g}$ & $-0.40^{*}$ & 0.04 & -0.11 & $-0.41^{* *}$ & -0.18 & -0.2 & -0.02 & 0.23 & & \\
\hline & Rph & $-0.38^{*}$ & 0.03 & -0.11 & $-0.37^{*}$ & -0.17 & -0.18 & -0.02 & 0.23 & & \\
\hline \multirow{2}{*}{ BY } & Rg & $-0.44^{*}$ & -0.06 & $0.47^{* *}$ & 0.08 & 0.19 & $0.49^{* *}$ & $0.50^{* *}$ & $0.53^{* *}$ & 0.01 & \\
\hline & Rph & $-0.42^{*}$ & -0.06 & $0.42^{* *}$ & 0.07 & 0.19 & $0.44^{* *}$ & $0.49^{* *}$ & $0.52^{* *}$ & 0.01 & \\
\hline \multirow{2}{*}{ GY } & Rg & $-0.39^{*}$ & -0.08 & $0.62^{* *}$ & 0.13 & 0.15 & $0.60^{* *}$ & $0.49^{* *}$ & $0.46^{* *}$ & -0.09 & $0.88^{* *}$ \\
\hline & Rph & $-0.35^{*}$ & -0.08 & $0.54^{* *}$ & 0.1 & 0.14 & $0.54^{* *}$ & $0.48^{* *}$ & $0.46^{* *}$ & -0.09 & $0.87^{* *}$ \\
\hline
\end{tabular}

DH: days to heading, PH: plant height, NT/P: number of tillers/plant, SD: stem diameter, SL: spike length, NS/S: number of spikelets/spike, NG/S: number of grains/spike, GW: grain weight/spike, TGW: 1000-grain weight, GY: grain yield (kg/fad), BY: biological yield $(\mathrm{kg} / \mathrm{fad})$.

Path analysis in connection with correlation is essential to assess the real contribution of each individual character toward the grain yield and confirm selection of the best that not completely reached by simple correlation alone. The results referring to path analysis in tables (7-9) assigned that except the traits of plant height, grain weight/spike and days to heading in F5; the last-mentioned trait beside number of grains/spike and 
1000 grain weight in F6 and the last referred character in F6 with days to heading and grain weight in F7 generation, all other studied characters exhibited positive direct effect on grain yield for all genotypes in all generations under investigation. Whereas the highest direct positive one induced by biological yield and number of tillers/plant in all generations; number of grains/spike, grain weight/spike as well as number of spikelets/spike in the F5, F6 and F7 generations, respectively. In the meantime, positive and highly significant correlations that obtained before for these characters with grain yield in all generations confirm that direct selection of these traits would be effective for having high yielding in the advanced generations under salinity. Likewise, the highest indirect effect on the grain yield was observed for grain weight (0.23), number of spikelets/spike (0.19) through number of grains/spike as well as number of tillers/plant (0.18) and number of grains/spike (0.15) with the biological yield in F5. However, as for F6 the grain weight/spike was 0.32 and the number of tillers/plant (0.26) via the biological yield; while grain weight/spike (0.38) and number of grains/spike (0.85) induced the same indirect effect in F7 generation by the biological yield also. Likewise, Eshghi et al. (2011), Mohtashami (2015), Tofiq et al. (2015 and 2016), Amardeep et al. (2017), Sunil et al. (2017), Malik et al. (2018), Matin et al. (2019) and Yadav et al. (2019) obtained similar results.

Table (7). Direct (diagonal) and indirect effect of important yield contributing traits on grain yield in generation F5

\begin{tabular}{cccccccccc}
\hline Trait & DH & PH & NT & NS & NG & GW & TGW & BY & $\begin{array}{c}\text { Correlation } \\
\text { with GY }\end{array}$ \\
\hline DH & $\mathbf{- 0 . 0 9}$ & -0.002 & -0.07 & -0.01 & -0.06 & 0.004 & -0.01 & -0.05 & -0.25 \\
PH & -0.01 & $\mathbf{- 0 . 0 2 7}$ & 0.06 & -0.02 & -0.02 & 0.000 & 0.02 & 0.01 & -0.04 \\
NT & 0.02 & -0.006 & $\mathbf{0 . 2 9}$ & 0.03 & 0.11 & -0.005 & -0.02 & 0.08 & 0.47 \\
NS & 0.01 & 0.005 & 0.07 & $\mathbf{0 . 1 2}$ & 0.19 & -0.009 & -0.01 & 0.07 & 0.41 \\
NG & 0.02 & 0.002 & 0.10 & 0.08 & $\mathbf{0 . 3 2}$ & -0.012 & -0.01 & 0.08 & 0.51 \\
GW & 0.02 & 0.000 & 0.09 & 0.07 & 0.23 & $-\mathbf{0 . 0 1 6}$ & 0.01 & 0.08 & 0.43 \\
TGW & 0.02 & -0.012 & -0.01 & -0.03 & -0.07 & -0.002 & $\mathbf{0 . 0 4}$ & -0.01 & -0.06 \\
BY & 0.03 & -0.002 & 0.18 & 0.05 & 0.15 & -0.008 & 0.00 & $\mathbf{0 . 4 3}$ & 0.83 \\
\hline
\end{tabular}

DH: days to heading, PH: plant height, NT/P: number of tillers/plant, NS/S: number of spikelets/spike, NG/S: number of grains/spike, GW: grain weight/spike, TGW: 1000-grain weight, BY: biological yield and GY: grain yield.

Egyptian J. Desert Res., 71, No. 1, 1-22 (2021) 
Table (8). Direct (diagonal) and indirect effect of important yield contributing traits on grain yield in generation F6.

\begin{tabular}{cccccccccc}
\hline Trait & $\mathbf{D H}$ & $\mathbf{P H}$ & $\mathbf{N T / P}$ & $\mathbf{N S} / \mathbf{S}$ & $\mathbf{N G} / \mathbf{S}$ & $\mathbf{G W}$ & $\mathbf{T G W}$ & $\mathbf{B Y}$ & $\begin{array}{c}\text { Correlation } \\
\text { with GY }\end{array}$ \\
\hline $\mathbf{D H}$ & $\mathbf{- 0 . 0 6}$ & -0.02 & -0.04 & -0.01 & 0.05 & -0.10 & 0.011 & -0.22 & -0.40 \\
$\mathbf{P H}$ & 0.01 & $\mathbf{0 . 1 2}$ & 0.02 & 0.01 & -0.02 & 0.02 & -0.003 & 0.19 & 0.34 \\
$\mathbf{N T} / \mathbf{P}$ & 0.01 & 0.01 & $\mathbf{0 . 2 7}$ & 0.06 & -0.08 & 0.14 & 0.001 & 0.26 & 0.66 \\
$\mathbf{N S} / \mathbf{S}$ & 0.01 & 0.00 & 0.08 & $\mathbf{0 . 1 9}$ & -0.11 & 0.12 & 0.006 & 0.24 & 0.53 \\
$\mathbf{N G / S}$ & 0.01 & 0.01 & 0.10 & 0.09 & $\mathbf{- 0 . 2 2}$ & 0.20 & 0.002 & 0.24 & 0.43 \\
GW & 0.03 & 0.01 & 0.14 & 0.08 & -0.17 & $\mathbf{0 . 2 6}$ & -0.009 & 0.32 & 0.66 \\
TGW & 0.02 & 0.01 & -0.01 & -0.03 & 0.01 & 0.05 & $\mathbf{- 0 . 0 4 3}$ & -0.01 & 0.01 \\
BY & 0.03 & 0.05 & 0.14 & 0.09 & -0.11 & 0.16 & 0.001 & $\mathbf{0 . 5 1}$ & 0.86 \\
\hline
\end{tabular}

DH: days to heading, PH: plant height, NT/P: number of tillers/plant, NS/S: number of spikelets/spike, NG/S: number of grains/spike, GW: grain weight/spike, TGW: 1000-grain weight, BY: biological yield and GY: grain yield.

Table (9). Direct (diagonal) and indirect effect of important yield contributing traits on grain yield in generation F7.

\begin{tabular}{cccccccccc}
\hline Trait & $\mathbf{D H}$ & $\mathbf{P H}$ & $\mathbf{N T} / \mathbf{P}$ & $\mathbf{N S} / \mathbf{S}$ & $\mathbf{N G / S}$ & $\mathbf{G W}$ & $\mathbf{T G W}$ & $\mathbf{B Y}$ & $\begin{array}{c}\text { Correlation } \\
\text { with GY }\end{array}$ \\
\hline $\mathbf{D H}$ & $\mathbf{- 0 . 0 5}$ & 0.001 & -0.02 & -0.01 & -0.004 & 0.03 & 0.033 & -0.33 & -0.35 \\
$\mathbf{P H}$ & -0.02 & $\mathbf{0 . 0 2 7}$ & -0.03 & -0.05 & -0.005 & 0.02 & -0.002 & -0.04 & -0.08 \\
NT/P & 0.01 & -0.003 & $\mathbf{0 . 1 9}$ & 0.06 & 0.005 & -0.02 & 0.006 & 0.30 & 0.54 \\
NS/S & 0.01 & -0.008 & 0.06 & $\mathbf{0 . 1 8}$ & 0.008 & -0.03 & 0.010 & 0.32 & 0.54 \\
NG/S & 0.01 & -0.009 & 0.06 & 0.10 & $\mathbf{0 . 0 1 5}$ & -0.06 & 0.001 & 0.35 & 0.48 \\
GW & 0.02 & -0.009 & 0.06 & 0.08 & 0.012 & $\mathbf{- 0 . 0 7}$ & -0.013 & 0.38 & 0.46 \\
TGW & 0.03 & 0.001 & -0.02 & -0.03 & -0.001 & -0.02 & $\mathbf{- 0 . 0 5 6}$ & 0.01 & -0.09 \\
BY & 0.03 & -0.002 & 0.08 & 0.08 & 0.008 & -0.04 & -0.001 & $\mathbf{0 . 7 2}$ & 0.87 \\
\hline
\end{tabular}

DH: days to heading, PH: plant height, NT/P: number of tillers/plant, NS/S: number of spikelets/spike, NG/S: number of grains/spike, GW: grain weight/spike, TGW: 1000-grain weight, BY: biological yield and GY: grain yield.

Moreover, principal components (PCs) were computed for determining the interrelationship among agronomic traits over the three generations (Fig. 2). The first two principal components (PC1 and PC2) displayed most of variance $84.25 \%$ (72.87 and $11.38 \%$ for PC1 and PC2, respectively). Therefore they were used in the biplot. The traits are represented by parallel or closely vectors that indicate a strong positive association, while the vectors approximately close (at $180^{\circ}$ ) display a very negative association. Besides, the vectors toward sides had expressed slight association. The results of PC-biplot displayed that number of tillers/plant, number of spikelets/spike, number of grains/spike, grain weight/spike, spike length and biological yield had a strong and consistent positive association with grain yield. These findings align with the results of genotypic and phenotypic correlations as well as path analysis indicate the importance of these traits in selection under salinity stress environments. Correspondingly,

Egyptian J. Desert Res., 71, No. 1, 1-22 (2021) 
El-Hendawy et al. (2017) and Mansour et al. (2020) demonstrated similar association of the aforementioned traits with grain yield under salinity stress.

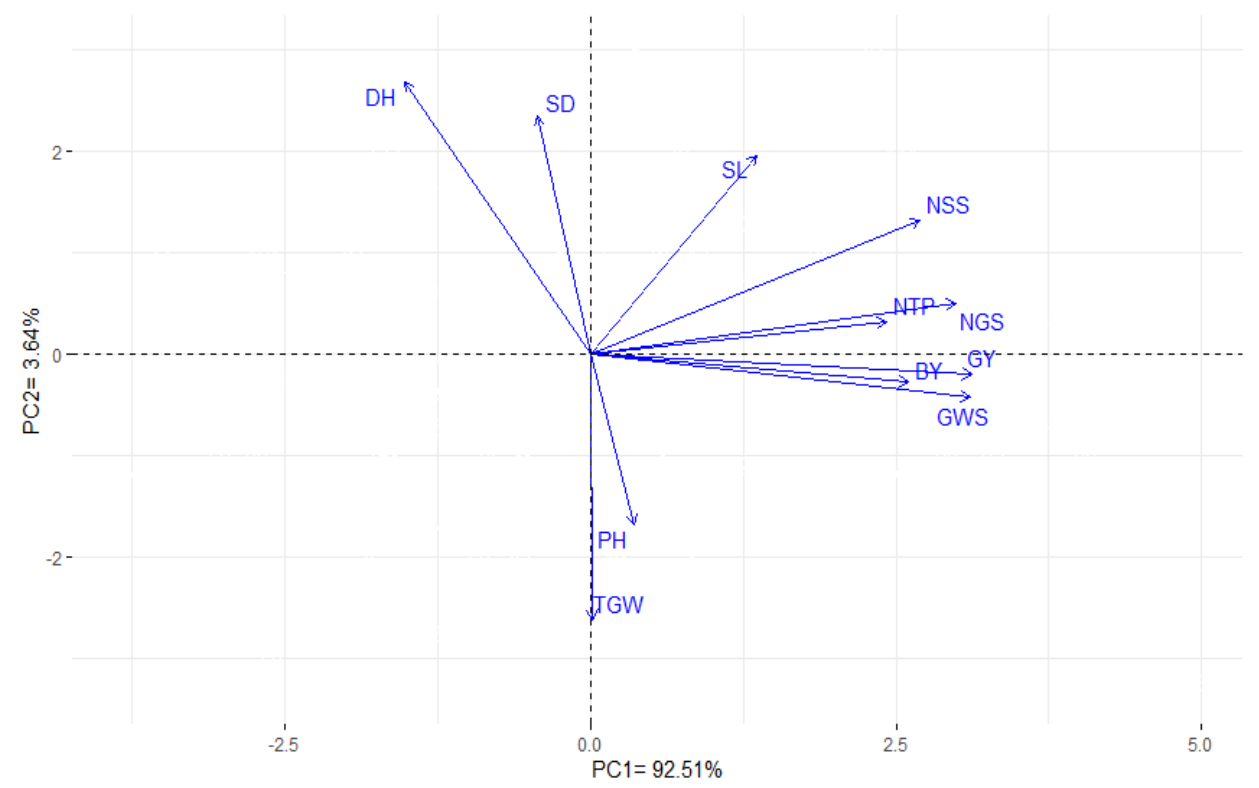

Fig. (2). Biplot of agronomic traits for fifty-two barley genotypes under salinity conditions. $\mathrm{DH}$ is days to heading, $\mathrm{PH}$ is plant height, NTP is number of tillers/plant, SD is stem diameter, SL is spike length, NSS is number of spikelets/spike, NGS is number of grains/spike, GWS grain weight/spike, TGW is 1000-grain weight, $\mathrm{GY}$ is grain yield $(\mathrm{kg} / \mathrm{fad}), \mathrm{BY}$ is biological yield $(\mathrm{kg} / \mathrm{fad})$.

From our findings it could be concluded that the characters of number of tillers/plant, number of grains/spike, grain weight/spike, number of spikelets/spike, biological yield and grain yield possessed true associations among each other and this indicates the usefulness of them in direct and indirect selections for development of high yielding genotypes in the progressive generations.

\section{REFERENCES}

Abdel-Ghani, A.H. (2013). Selection of high yielding lines from heterogeneous Jordanian barley landraces under well watered and drought stress conditions. Bull. Fac. Agric., Cairo Univ., 64:13-29.

Abdel-Ghany, A.H., H.K. Parzies, S. Ceccarelli, S. Grando and H.H. Geiger (2005). Estimation of quantitative genetic parameters for outcrossing-related traits in barley. Crop Sci., 45: 98-105.

Egyptian J. Desert Res., 71, No. 1, 1-22 (2021) 
Gonzalez A., I. Martin and L. Ayerbe (1999). Barley yield in water-stress condition. The influence of precocity, osmotic adjustment and stomatal conductance. Field Crop Res., 62: 23-34.

Akram, Z., S.U. Ajmal and M. Munir (2008). Estimation of correlation coefficient among some yield parameters of wheat under rainfed conditions. Pak. J. Bot., 40 (4): 1777-1781.

Allel, D., A. Benamar, M. Badri and C. Abdelly (2019). Evaluation of salinity tolerance indices in North African barley accessions at reproductive stage. Czech Journal of Genetics and Plant Breeding, 55 (2): 61-69.

Amardeep, L., S. Vishwanath and P. Malik (2017). Studies on correlation and path analysis in barley (Hordeum vulgare L.). Bull. Env. Pharmacol. Life Sci., 6 (12): 75-80.

Arshadi, A.E., E. Karami, A. Sartip and M. Zare (2018). Application of secondary traits of barley for identification of drought tolerant genotypes in multi-environmental trials. Aust. J. Crop Sci., 12: 157167.

Badr, A., K. Miiler, R. Schafer-Pregl, H. El-Rabey, S. Effgen, H.H. Ibrahim, C. Pozzi, W. Rohde and F. Salamini (2000). On the origin and domestication history of barley (Hordeum vulgare). Mol. Biol. Evol., 17 (4): 499-510.

Baik, B.K. and S.E. Ullrich (2008). Barley for food: characteristics, improvement and renewed interest. Journal of Cereal Science, 48 (2): 233-242.

Barnabas, B., K. Jager and A. Feher (2008). The effect of drought and heat stress on reproductive processes in cereals. Plant Cell Environ., 31: 11-38.

Bhatty, R.S. (1999). The potential of hall-less barley. Cer. Chem., 76: 589599.

Blattner, F.R. and M. Badani (2001). RAPD data do not support a second centre of barley domestication in Morocco. Genetic Resources and Crop Evolution, 48 (1): 13-19.

Bothmer, R.T. Hintum, H. Knupffer and K. Sato (2003). In: "Diversity in barley (Hordeum vulgare)". Developments in Plant Genetics and Breeding, Vol. 7, 633 p.

Ceccarell, S., A. Lutf, A. Sarkar, M. Abdelali-Martini, E. Abdulhakim and S. Grando (2008). Gender-sensitive participatory evaluation of barely and lentil cultivars in Yemen. II. Cultivars Development. J. Agricultural Sci., 148 (6): 627-638.

Chandra, S., S.N. Nigam, A.W. Cruickshank, A. Bandyopadhyaya and S. Harikrishna (2003). Selection index for identifying high-yielding groundnut genotypes in irrigated and rainfed environments. Annl. Appl. Biol., 143: 303-310. 
Dewey, D.R. and K.H. Lu (1959). A correlation and path coefficient analysis of components of crested wheat grass seed production. Agron. J., 51: 515-518.

Dyulgerova, B. and N. Dyulgerov (2020). Grain yield and yield related traits of sodium azide include barley mutant lines. Journal of Central European Agriculture, 21(1): 83-91.

El-Banna, M.N., M.A.A. Nassar, M.N. Mohamed and M.A. Boseely (2011). Evaluation of 16 barley genotypes under calcareous soil condition in Egypt. J. Agric. Sci., 3 (1): 105-121.

El-Hendawy, S.E., W.M. Hassan, N.A. Al-Suhaibani, Y. Refay and K.A. Abdella (2017). Comparative performance of multivariable agrophysiological parameters for detecting salt tolerance of wheat cultivars under simulated saline field growing conditions. Front. Plant Sci., 8: Article no. 435.

El-Raey, M. (1997). Vulnerability assessment of the coastal zone of the Nile delta of Egypt, to the impacts of sea level rise. Ocean and Coastal Management, 37 (1): 29-40.

Eshghi, R., J. Ojaghi and S. Salayeva (2011). Genetic gain through selection indices in hulless barley. Int. J. Agric. Biol., 13 (2): 191-197.

Falconer, D.S. (1989). In: "Introduction to Quantitative Genetics". Longman Group Ltd., London.

Falconer, D.S. and T.F.C. Mackay (1996). In: "Introduction to Quantitative Genetics", $4^{\text {th }}$ edition. Benjamin Cummings, England.

FAOSTAT, D. (2020). Food and Agriculture Organization of the United Nations. Statistical Database. (Accessed 13 December 2020).

Ghimire, N.H. and P.M. Mahat (2019). Variability, heritability and genetic advance of advanced breeding lines of barley (Hordeum vulgare L.) under mountain environment of Nepal. Int. J. Adv. Res. Biol. Sci., 6 (11): 34-42.

Gomez, K.A. and A.A. Gomez (1984). In: "Statistical Procedures for Agriculture Research", $2^{\text {nd }}$ Ed. John Wiley and Sons Inc., New York, USA.

Griffey, C. (1999). In: "Hull-less as an Improved Feed Crop". Kuntucky Small Grain Breeder. pp. 423-430.

Hailu, A., S. Alamerew, M. Nigussie and E. Assefa (2016). Genetic variability, heritability and genetic advance for yield and yield related traits in barley (Hordeum vulgare L.) germplasm. World J. Agri. Sci., 12 (1): 36-44.

Hammami, Z., H. Sbei, K. Kadri, Z. Jmel, A. Sahli, M. Belhaj Fraj, H. Naser, J.A. Teixeira da Silva and Y. Trifa (2016). Evaluation of performance of different barley genotypes irrigated with saline water in South Tunisian Saharan conditions. Environ. Exp. Bot., 14: 1521.

Egyptian J. Desert Res., 71, No. 1, 1-22 (2021) 
Jamshidi, A. and H.R. Javanmard (2018). Evaluation of barley (Hordeum vulgare L.) genotypes for salinity tolerance under field conditions using the stress indices. Ain Shams Engineering Journal, 9: 20932099.

Jaradat, A.A., M.A. Shahid and A. Al-Maskari (2004). Genetic diversity in Batini barley landrace for Oman: Response to salinity stress. Crop Sci., 44: 997-1007.

Kashif, M. and I. Khaliq (2004). Heritability, correlation and path coefficient analysis for some metric traits in wheat. Inter. J Agri. Biol., 6 (1): 138-142.

Kwon, S.H. and J.H. Torrie (1964). Heritability and interrelationships among traits of two soybean populations. Crop Sci., 4: 196-198.

Lobell, D., M. Burke, C. Tebaldi, M. Mastrandrea, W. Falco and R. Naylor (2008). Prioritizing climate change adaptation needs for food security in 2030. Science, 319: 607-610.

Malik, P., S.K. Singh, L. Singh, S. Kumar, P.K. Gupta, R.K. Yadav, Amardeep and A. Kumar (2018). Correlation and path analysis for seed yield and its contributing character in barley (Hurdeum vulgare L.). Int. J. Pure App. Biosci., 6 (6): 875-879.

Mansour, E., M.I. Abdul-Hamid, M.T. Yasin, N. Qabil and A. Attia (2017). Identifying drought-tolerant genotypes of barley and their responses to various irrigation levels in a Mediterranean environment. Agric. Water Manag., 194: 58-67.

Mansour, E., E.S. Moustafa, E.S.M. Desoky, M. Ali, M.A. Yasin, A. Attia, N. Alsuhaibani, M.U. Tahir and S. El-Hendawy (2020). Multidimensional evaluation for detecting salt tolerance of bread wheat genotypes under actual saline field growing conditions. Plants, 9 (10): Article no. 1324.

Matin, M.Q.I., M. Amiruzzaman, M. Billah, M.B. Banu, N. Naher and D.A. Choudhury (2019). Genetic variability and path analysis studies in barley (Hordum Vulgare L.). Int. J. Appl. Sci. Biotechnol., 7 (2): 243-247.

Mohammadi, R., M. Armion, D. Kahrizi and A. Armi (2010). Efficacy of screening techniques for durum wheat genotypes under mild drought condition. Int. J. Plant Product., 4: 11-24.

Mohtashami, R. (2015). The correlation study of important barley agronomic traits and grain yield by path analysis. Biological Forum, 7 (1): 1211-1219.

Naghii, V. and M.R. Asgharipourm (2011). Different in drought stress responses of 20 barley genotypes with contrasting drought tolerance during grain filling. Advances in Environmental Biology, 5 (9): 3042-3049. 
Orabi J., G. Backes, A. Wolday, A. Yahyaoui and A. Jahoor (2007). The Horn of Africa as a center of barley diversification and a potential domestication site. Theor. Appl. Genet., 114: 1117-1127.

Oraby, M.A., A.A. El-Khawaga, E. Mansour and M.A. Megahed (2018). Assessing of drought tolerance of sixteen barley genotypes under different irrigation treatments. Zag. J. Agric. Res., 45 (4).

Rabiei, B., M. Valizadeh, B. Ghareyazie and M. Moghaddam (2004). Evaluation of selection indices for improving rice grain shape. Field Crops Res., 89: 359-367.

Reisdorph, N.A. and K.I. Koster (1999). Progressive loss of desiccation tolerance in germination pea (Pisum astivum) seeds. Physiologica Plantarum, 105: 266-271.

Rezaei, A.M. and A.M. Yousefi (2008). Comparison of direct and indirect selection methods based on selection indices in wheat lines in drought and non-drought conditions. J. Sci. Technol. Agric. Nat. Resour., 12: 21-32.

Sabouri, H., B. Rabiei and M. Fazlalipour (2008). Use of selection indices based on multivariate analysis for improving grain yield in rice. Rice Sci., 15: 303-310.

SAS (2003). Statistical Analysis System. SAS Release 9.1 for windows, SAS Institute Inc. Cary, NC, USA.

Savii, G. and G. Nedelea (2012). Estimation of interrelationships among different yield traits in winter wheat. Journal of Horticulture, Forestry and Biotechnology, 16 (1): 115-118.

Schmidhalter, U., M. Evequoz, K.H. Camp and C. Studer (1998). Sequence of drought response of maize seedlings in drying soil. Physiologica Plantarum, 104: 159-168.

Shrimali, J., A.S. Shekhawat and S. Kumari (2017). Genetic variation and heritability studies for yield and yield components in barley genotypes under normal and limited moisture conditions. J. Pharmacogn. Phytochem., 6: 233-235.

Siahpoosh, M.R., M.T. Assad, Y. Emam and A. Saidi (2001). Implication of four selection indices in wheat cultivars (Triticum aestivum L.) for increasing the grain yield. Indian J. Genet., 32: 219-236.

Singh, T. and H.S. Balyan (2003). Relative efficiency of various single plant selection criteria and F3 generation yield testing in wheat (Triticum aestivum L.). Indian J. Genet., 63: 24-29.

Sivasubramanian, S. and P. Madhavamenon (1973). Genotypic and phenotypic variability in rice. Madras Agricultural Journal, 60: 1093-1096.

Srivastava, V., M.A. Akbudak and S. Nandy (2011). Marker-Free plant transformation. In: "Dan, Y. and D.W. OW (Eds.)". Plant Transformation Technology. Revolution in Last Three Decades, pp. $108-122$.

Egyptian J. Desert Res., 71, No. 1, 1-22 (2021) 
Steel, R.G.D., J.H. Torrie and D.A. Dickey (1997). In: "Principals and Procedures of Statistics: A Biometrical Approach", $3{ }^{\text {rd }}$ Ed. McGrawHill: New York, pp. 172-177.

Sunil, K.D. Sehrawat and M. Khan (2017). Evaluation of character association in barley (Hordeum vulgare L.) genotypes for yield and yield related traits. Cur. J. Appl. Sci. Technol., 24 (1): 1-9.

Tofiq, S.E., T.N.H. Amin, S.M.S. Abdulla and D.A. Abdulkhaleq (2015). Correlation and path coefficient analysis of grain yield and yield components in some barley genotypes created by full diallel analysis in Sulaimani region for F2 generation. International Journal of Plant, Animal and Environmental Sciences, 5 (4): 76-79.

Tofiq, S.I., D.A. Abdulkhaleq, S.G. Hama and S.H. Abdulqader (2016). Correlation and path analysis in barley under rainfall conditions. Journal of Zankoi Sulaimani, part A, 18 (3): 111-118.

Trethowan, R.M., M.A. Turner and T.M. Chatth (2010). In: "Breeding Strategies to Adapt Crops to a Changing Climate". Climate Change and Food Security, pp.155-174.

Walker, J.T. (1960). The use of selection index technique in the analysis of progeny, new data. Emp. Cott. Gr. Rev., 37: 81-107.

Yadav, K., K.N. Maurya, S.P. Shrivastava, V. Singh, K. Lal, S.K. Maurya and H. Yadav (2019). Assessment of genetic variability, correlation and path coefficient for yield and its contributing traits in exotic and in digenous barley (Hordeum vulgare L.). International Journal of Chemical Studies, 7 (2): 1584-1587.

Zohary, D. and M. Hopf (1993). In: "Domestication of Plants in the Old World". The Origin and Spread of Cultivated Plants in the West Asia, Europe and Nile Valley. Clarendon Press, Oxford, England.

Zhou, M.X. (2009). In: "Barley Production and Consumption". Genetics and Improvement of Barley Malt Quality. Springer, Berlin, Heidelberg, pp. 1-17.

Zhu, J., Y. Fan, S. Shabala, C. Li, C. Lv, B. Guo, R. Xu and M. Zhou (2020). Understanding mechanisms of salinity tolerance in barley by proteomic and biochemical analysis of near-isogenic lines. Int. J. Mol. Sci., 21: 1516-1529. 


\title{
تقدير التباين الوراثي والإرتباط بين صفات المحصول في سلالات الثعير المتقدمة تحت ظروف الملوحة
}

\author{
إيهاب سعودي عبد الحميد مصطقى الإنى \\ وحدة تربية النباتات، قسم الأصول الور اثية، مركز بحوث الصحر اء، المطرية، القاهرة،
}

إن الحصول على محاصيل مقاومة للإجهاد بات أمرًا حتميًا لمواجهة التزايد المستمر للكتلة

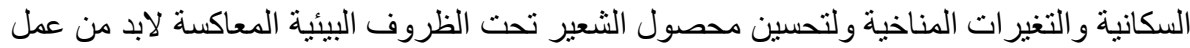

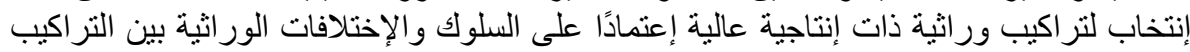

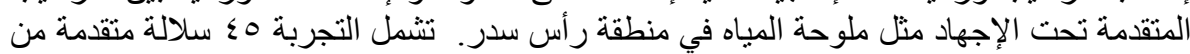

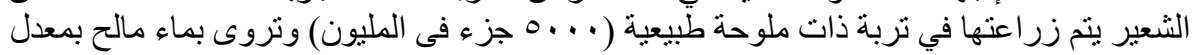

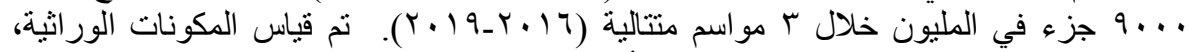

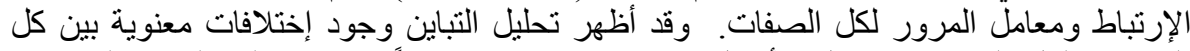

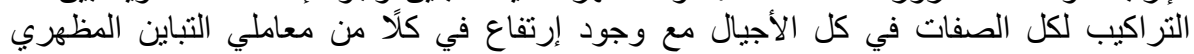

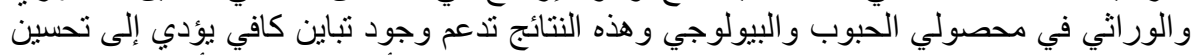

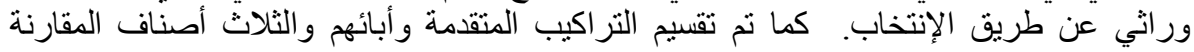

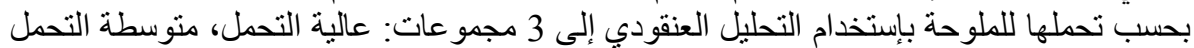

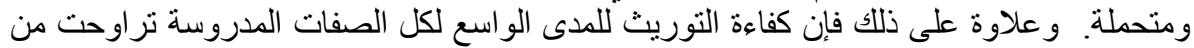

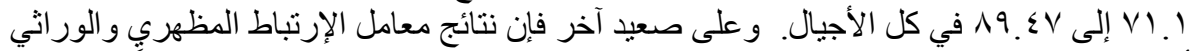

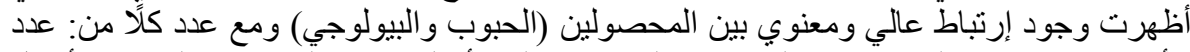

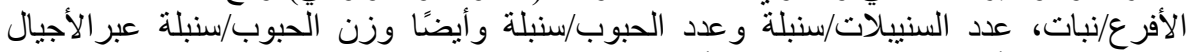

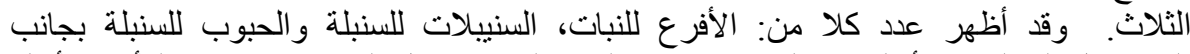

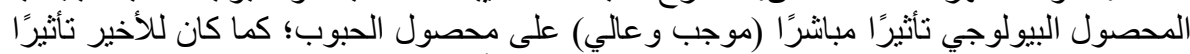

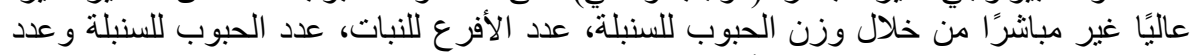
السنييلات للسنبلة وهذا كله يعكس أهمية هذه الصفات لتحسين المحصول تحت ظروف الإنس لإجهاد 